\title{
RANCANG BANGUN ALAT GASIFIKASI BIOMASSA (KAYU KARET) SISTEM UPDRAFT SINGLE GAS OUTLET
}

\section{DESIGN OF BIOMASS GASIFICATION EQUIPMENT (RUBBER WOOD) UPDRAFT SINGLE GAS OUTLET SYSTEM}

\author{
Indah Pratiwi ${ }^{1)}$ \\ ${ }^{1)}$ Program Studi Teknik Analisis Laboratorium Migas Politeknik Akamigas Palembang, 30257, Indonesia \\ Corresponding Author E-mail: indahpratiwikimia@gmail.com
}

\begin{abstract}
Utilization of biomass waste as an alternative energy source is needed now seeing the use of fossil fuels increases with the development of technology. The step that must be done is to find alternative fuels through the gasification process. Gasification is one alternative energy solution that converts solid material in this case in the form of biomass into flammable gas. The gases produced include $\mathrm{CO}, \mathrm{H}_{2}$, and $\mathrm{CH}_{4}$. The biomass used in this study is rubber wood that is old and unable to produce anymore. In the gasification process, the resulting syngas still has impurities such as ash and tar. This study will examine the effect of variations in water flow rate on the wet scrubber venturi that is used to clean syngas from tar. The flow rate is varied by $0.015 \mathrm{~m}^{3} / \mathrm{min}, 0.02 \mathrm{~m}^{3} / \mathrm{min}$ and $0.025 \mathrm{~m}^{3} / \mathrm{min}$. The test results obtained that the weight of tar caught were respectively $0.67 \mathrm{~g}, 0.97 \mathrm{~g}$ and $1.7 \mathrm{~g}$ with a $70 \%$ wet scrubber efficiency level. Besides that, the syngas that passes through the wet scrubber venturi also experienced changes in the composition of syngas consisting of $\mathrm{CO} 10.15 \%, \mathrm{H}_{2} 3.74 \%$ and $\mathrm{CH}_{4} 2.62 \%$ and changed to $\mathrm{CO} 9,05 \%, \mathrm{H}_{2} 3.43 \%$ and $\mathrm{CH}_{4} 4,11 \%$. With this change in syngas composition, an increase in the syngas LHV value of $2,625 \mathrm{MJ} / \mathrm{m}^{3}$ increased to $2,987 \mathrm{MJ} /$ $\mathrm{m}^{3}$.
\end{abstract}

Keywords: Gasification, Rubber Wood, Tar, Syngas and Ventri wet Scrubber

Abstrak: Pemanfaatan limbah biomassa sebagai sumber energi alternatif diperlukan saat ini melihat penggunaan bahan bakar fosil meingkat seriing berkembangnya teknlogi. Langkah yang harus dilakukan ialah mencari bahan bakar alternatif melalui proses gasifikasi. Gasifikasi adalah salah satu solusi energi alternatif yang mengkonversi bahan padat dalam hal ini berupa biomassa menjadi gas yang mudah terbakar. Gas-gas yang dihasilkan antara lain $\mathrm{CO}, \mathrm{H}_{2}$, dan $\mathrm{CH}_{4}$. Biomassa yang dimanfaatkan dalam penelitian ini adalah kayu karet yang sudah tua dan tidak mampu berproduksi lagi. Pada proses gasifikasi, syngas yang dihasilkan masih terdapat pengotor seperti abu dan tar. Penelitian ini akan menguji pengaruh variasi laju alir air pada venturi wet scrubber yang digunakan untuk membersihkan syngas dari tar. Laju alir divariasikan sebesar 0,015 $\mathrm{m}^{3} / \mathrm{min}, 0,02 \mathrm{~m}^{3} / \mathrm{min}$ dan 0,025 $\mathrm{m}^{3} / \mathrm{min}$. Dari hasil pengujian didapatkan berat tar yang tertangkap secara berturut, yaitu: 0,67 g, 0,97 g dan $1,7 \mathrm{~g}$ dengan tingkat efisiensi wet scrubber $70 \%$. Disamping itu syngas yang melewati venturi wet scrubber juga mengalami perubahan komposisi syngas terdiri dari $\mathrm{CO}$ 10,15\%, $\mathrm{H}_{2} 3,74 \%$ serta $\mathrm{CH}_{4} 2,62 \%$ dan berubah menjadi $\mathrm{CO} 9,05 \%, \mathrm{H}_{2} 3,43 \%$ dan $\mathrm{CH}_{4}$ 4,11\%. Dengan adanya perubahan komposisi syngas ini, maka terjadi peningkatan pada nilai LHV syngas yaitu 2,625 $\mathrm{MJ} / \mathrm{m}^{3}$ meningkat menjadi 2,987 $\mathrm{MJ} / \mathrm{m}^{3}$.

Kata Kunci : Gasifikasi, Kayu Karet, Tar, Syngas dan Ventri wet Scrubber

\section{PENDAHULUAN}

Dewasa ini penggunaan bahan bakar minyak (BBM) semakin meningkat seiring dengan percepatan pembangunan dan transportasi yang membuat peningkatan dalam penggunaan energi. Namun hal ini tidak sejalan dengan cadangan minyak bumi kita yang semakin menipis. Diperkirakan cadangan minyak bumi di Indonesia hanya bertahan hanya sampai 15 tahun kedepan jika konsumsi BBM tetap tinggi sama seperti sekarang.
Beberapa energi alternatif telah dikembangkan, namun terkendala biaya produksi yang masih terlalu tinggi.

Sebelum ditemukannya cadangan minyak yang besar pada tahun 1940-an, negara-negara di Eropa telah menggunakan energi alternatif sebagai bahan bakar untuk menggerakkan mesin-mesin industri, pembangkit dan transportasi. Bahan bakar yang digunakan adalah berasal dari gasifikadi dari biomassa seperti kayu dan limbah 
biomassa lainnya. Alat ini dikenal dengan nama generator gas kayu (Wood Gas Generator).

Dibidang teknik kimia, gasifikasi sebagai teknik untuk mengkonversi bahan bakar padar menjadi gas. Gas yang dihasilkan dihasilkan pada gasifikasi disebut gas mampu bakar (syngas) yang kandungannya didominasi olaeh gas $\mathrm{CO}, \mathrm{H}_{2}$, dan $\mathrm{CH}_{4}$. Reaktor tersebut dikenal dengan nama gasifier. Ketika gasifikasi dilangsungkan, terjadi kontak antara bahan bakar dengan medium penggasifikasi di dalam gasifier. Kontak antara bahan bakar dengan medium tersebut menetukan jenis gasifier yang digunakan. Sedangkan bahan bakar padat atau biomassa yang digunakan adalah kayu karet. Biomassa (biomass) merupakan sumber energi yang potensial karena sifatnya yang dapat diperbarui (renewble).

Sumatera Selatan merupakan salah satu daerah penghasil kayu karet, sangat tepat apabila dimanfaatkan. Data perkebunan pada tahun 2007 menujukan 9.500 ha per tahun karet tua. Sehingga pemanfaatan kayu karet sebagai bahan bakar biomassa tidak akan menggangu komiditi yang lain seperti industri furniture. Syngas yang dihasilkan dari bahan bakar kayu karet mencapai 20,47\% CO, 7,95\% $\mathrm{H}_{2}$, dan $1,25 \% \mathrm{CH}_{4}$ dan LHV 3,859 $\mathrm{MJ} / \mathrm{m}^{3}$ (Kurniawan, 2012).

Allin Indri pada tahun 2009 telah melakukan perancangan gasifier tipe updraft berbahan bakar batubara. Dari hasil penelitian ini efisiensi gasifier mencapai $76 \%$. Namun hasil penelitian pada updraft gasifier menunjukan masih terkandung banyak tar yang dihasilkan dan belum ada penanganan yang dilakukan. Ini ditunjukan dari hasil penelitian Guswendar (2012) yang mengatakan bahwa updraft double gas outlet gasifier berbahan bakar kayu karet yang dibuatnya masih mengandung tar. Tar merupakan produk sampingan hasil dari proses gasifikasi,dan ini terlihat banyak menempel di sepanjang pipa aliran syngas. Kandungan tar yang dihasilkan dari proses gasifikasi menggunakan updraft gasifier berbahan bakar kayu karet mencapai 114,53 $\mathrm{g} / \mathrm{m}^{3}$ (Ardyan,2012).

Angka ini cukup tinggi dan jelas dibutuhkan penanganan untuk mengatasi kandungan tar pada syngas. Salah satu metode untuk membersihkan syngas adalah dengan memasang gas cleaning seperti venturi wet srubber. Wet scrubber berfungsi untuk memisahkan tar yang terkandung dalam syngas sekaligus mendinginkan syngas dengan media pembersih yang digunakan adalah air. Air akan mengangkat partikel dengan menangkapnya dalam tetesan air. Syngas yang bersih dan bertemperatur rendah dapat diaplikasikan pada mesin pembakaran internal seperti diesel. Berdasarkan penelitian diatas akan dilakukan perancangan reaktor gasifikasi untuk mendapatkan gas mampu bakar (syngas) dengan metode updraft gasifier dengan menambahkan venturi wet scrubber yang merupakan modifikasi rancangan dari para peneliti sebelumnya. Diharapkan nantinya dapat dihasilkan reaktor gasifikasi dengan menggunakan bahan bakar biomassa (kayu karet) yang dapat berguna untuk mengatasi kebutuhan energi.

\section{TEORI DASAR \\ 2.1 Gasifikasi}

Gasifikasi adalah suatu teknologi proses konversi bahan padat menjadi gas yang mudah terbakar. Bahan padat yang dimaksud adalah bahan bakar padat misalnya, biomassa, batubara, dan arang yang mengandung karbon (C), sedangkan gas yang dimaksud adalah gasgas yang dihasilkan dari proses gasifikasi seperti $\mathrm{CO}, \mathrm{H}_{2}$, dan $\mathrm{CH}_{4}$. Melalui gasifikasi, kita dapat mengkonversi hampir semua bahan organik kering menjadi bahan bakar, sehingga dapat menggantikan bahan bakar fosil sebagai sumber bahan bakar. Bahan baku untuk proses gasifikasi dapat berupa limbah biomassa, yaitu potongan kayu, tempurung kelapa, sekam padi maupun limbah pertanian lainnya.

Gasifikasi umumnya terdiri dari empat proses, yaitu pengeringan, pirolisis, oksidasi, dan reduksi. Pada gasifier jenis unggun terfluidakan, kontak yang terjadi saat pencampuran antara gas dan padatan sangat 
kuat sehingga perbedaan zona pengeringan, pirolisis, oksidasi, dan reduksi tidak dapat dibedakan. Salah satu cara untuk mengetahui proses yang berlangsung pada gasifier jenis ini adalah dengan mengetahui rentang temperatur masing-masing proses, yaitu:

a. Pengeringan: $\mathrm{T}>150{ }^{\circ} \mathrm{C}$

b. Pirolisis/Devolatilisasi: $150^{\circ} \mathrm{C}<\mathrm{T}<700^{\circ} \mathrm{C}$

c. Oksidasi: $700^{\circ} \mathrm{C}<\mathrm{T}<1.500^{\circ} \mathrm{C}$

d. Reduksi: $800^{\circ} \mathrm{C}<\mathrm{T}<1.000{ }^{\circ} \mathrm{C}$

Proses pengeringan, pirolisis, dan reduksi bersifat menyerap panas (endotermik), sedangkan proses oksidasi bersifat melepas panas (eksotermik). Pada pengeringan, kandungan air pada bahan bakar padat diuapkan oleh panas yang diserap dari proses oksidasi. Pada pirolisis, pemisahan volatile matters (uap air, cairan organik, dan gas yang tidak terkondensasi) dari arang atau padatan karbon bahan bakar juga menggunakan panas yang diserap dari proses oksidasi.

Pembakaran mengoksidasi kandungan karbon dan hidrogen yang terdapat pada bahan bakar dengan reaksi eksotermik, sedangkan gasifikasi mereduksi hasil pembakaran menjadi gas bakar dengan reaksi endotermik.

\subsection{Proses Pengeringan (Drying)}

Reaksi ini terletak pada bagian atas reaktor dan merupakan zona dengan temperatur paling rendah di dalam reaktor yaitu di bawah $150^{\circ} \mathrm{C}$. Proses pengeringan ini sangat penting dilakukan agar pengapian pada burner dapat terjadi lebih cepat dan lebih stabil. Pada reaksi ini, bahan bakar yang mengandung air akan dihilangkan dengan cara diuapkan dan dibutuhkan energy sekitar 2.260 $\mathrm{kJ}$ untuk melakukan proses tersebut sehingga cukup menyita waktu operasi.

Menurut Kurniawan (2012), penelitian yang telah dilakukannya menunjukan bahwa pengeringan manual oleh sinar matahari berperan penting dalam mempercepat proses pengeringan didalam reaktor oleh panas reaksi pembakaran (oksidasi). Penjemuran dengan sinar matahari pada suhu diatas $32^{\circ} \mathrm{C}$ selama dua jam dapat mempercepat waktu pengeringan di dalam reaktor hingga $30 \%$ atau kurang dari 25 menit. Jika dibandingkan dengan penjemuran pada suhu $30^{\circ} \mathrm{C}$ yang mencapai 25-40 menit untuk proses pengeringan saja.

\subsection{Pirolisis}

Pirolisis atau devolatilisasi disebut juga sebagai gasifikasi parsial. Suatu rangkaian proses fisik dan kimia terjadi selama proses pirolisis yang dimulai secara lambat pada $\mathrm{T}<$ $350^{\circ} \mathrm{C}$ dan terjadi secara cepat pada $\mathrm{T}>$ $700^{\circ} \mathrm{C}$. Ketika suhu pada zona pirolisis rendah maka akan dihasilkan banyak arang dan sedikit cairan (air, hidrokarbon dan tar). Komposisi produk yang tersusun merupakan fungsi temperatur, tekanan, dan komposisi gas selama pirolisis berlangsung.

Proses pirolisis dimulai pada temperatur sekitar $230^{\circ} \mathrm{C}$, ketika komponen yang tidak stabil secara termal, seperti lignin pada biomassa dan volatile matters pada batubara, pecah dan menguap bersamaan dengan komponen lainnya. Produk cair yang menguap mengandung tar dan PAH (polyaromatic hydrocarbon). Produk pirolisis umumnya terdiri dari tiga jenis, yaitu gas ringan $\left(\mathrm{H}_{2}, \mathrm{CO}, \mathrm{CO}_{2}, \mathrm{H}_{2} \mathrm{O}\right.$, dan $\left.\mathrm{CH}_{4}\right)$, tar, dan arang.

\subsection{Reduksi (Gasifikasi)}

Reduksi atau gasifikasi melibatkan suatu rangkaian reaksi endotermik yang disokong oleh panas yang diproduksi dari reaksi pembakaran. Reduksi terjadi pada suhu $<800^{\circ} \mathrm{C}$ dan menghasilkan gas mampu bakar (syngas) berupa $\mathrm{H}_{2}, \mathrm{CO}$, dan $\mathrm{CH}_{4}$.

\subsection{Oksidasi (Pembakaran)}

Oksidasi atau pembakaran arang merupakan reaksi terpenting yang terjadi di dalam gasifier. Proses ini menyediakan seluruh energi panas yang dibutuhkan pada reaksi endotermik. Oksigen yang dipasok ke dalam gasifier bereaksi dengan substansi yang mudah terbakar. Hasil reaksi tersebut adalah $\mathrm{CO}_{2}$ dan $\mathrm{H}_{2} \mathrm{O}$ yang secara berurutan direduksi ketika kontak dengan arang yang diproduksi pada pirolisis.

\subsection{Jenis-jenis Alat Gasifikasi (Gasifier)}


Terdapat dua tipe utama gasifikasi (gasifier), yakni tipe fluidized bed dan tipe fixed bed. Beberapa tipe fixed bed gasifier, jika ditinjau dari arah aliran udara, gasifier dibagi menjadi tiga tipe, yakni downdraft, updraft, dan crossdraft. Ketiga tipe fixed bed gasifier sebagai berikut .

\section{Updraft gasifier}

Updraft gasifier merupakan reaktor gasifikasi yang umum digunakan secara luas. Ciri khas dari reaktor gasifikasi ini adalah aliran udara dari blower masuk melalui bagian bawah reaktor melalui grate sedangkan aliram bahan bakar masuk dari bagian atas reaktor sehingga arah aliran udara dan bahan bakar memiliki prinsip yang berlawanan (counter current). Produksi gas dikeluarkam melalui bagian atas dari reaktor sedangkan abu pembakaran jatuh ke bagian bawah gasifier karena pengaruh gaya gravitasi dan berat jenis abu. Di dalam reaktor, terjadi zonafikasi area pembakaran berdasarkan pada distribusi temperatur reaktor gasifikasi. Zona pembakaran terjadi di dekat grate yang dilanjutkan dengan zona reduksi yang akan menghasilkan gas dengan temperatur yang tinggi. Gas hasil reaksi tersebut akan bergerak menuju bagian atas dari reaktor yang memiliki temperatur lebih rendah dan gas tersebut akan kontak dengan bahan bakar yang bergerak turun sehingga terjadi proses pirolisis dan pertukaran panas antara gas dengan temperatur tinggi terhadap bahan bakar yang memiliki temperatur lebih rendah.

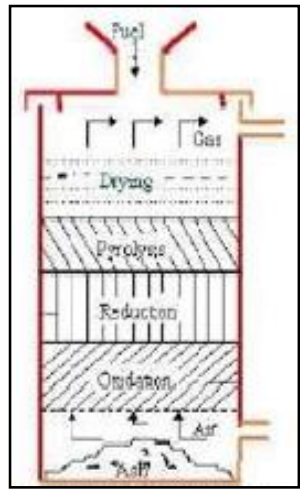

Gambar 2.1 Updraft Gasifier

Panas sensible yang diberikan gas digunakan bahan bakar untuk pemanasan awal dan pengeringan bahan bakar. Kedua proses tersebut, yaitu proses pirolisis dan proses pengeringan terjadi pada bagian teratas dari reaktor gasifikasi.

\section{Downdraft gasifier}

Sistem gasifikasi downdraft memiliki system yang hamper sama dengan sistem gasifikasi updraft, yaitu dengan memanfaatkan sistem oksidasi tertutup untuk memperoleh temperatur tinggi. Bahan bakar dalam reaktor gasifikasi downdraft dimasukkan dari atas reactor dan udara dari blower dihembuskan dari samping menuju ke zona oksidasi sedangkan syngas hasil pembakaran keluar melalui burner yang terletak di bawah ruangan bahan bakar sehingga saat awal gas akan mengalir ke atas dan saat volume gas makin meningkat, maka syngas mencari jalan keluar melalui daerah dengan tekanan yang lebih rendah. Sistem tersebut memiliki maksud agar syngas yang terbentuk akan tersaring kembali oleh bahan bakar dan melalui zona pirolisis sehingga tingkat kandungan tar dalam gas dapat dikurangi. Untuk menghindari penyumbatan gas di dalam reaktor, maka digunakan blower hisap untuk menarik syngas dan mengalirkannya ke arah burner.

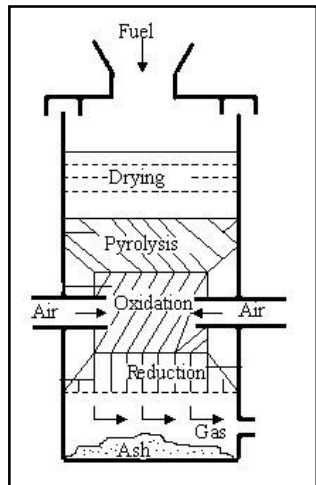

Gambar 2.2 Downdraft Gasifier

\section{Crossdraft gasifier}

Pada crossdraft gasifier, udara disemprotkan ke dalam ruang bakar dari lubang arah samping yang saling berhadapan dengan lubang pengambilan gas sehingga pembakaran dapat terkonsentrasi pada satu bagian saja dan berlangsung secara lebih banyak dalam suatu satuan waktu tertentu. 
Sistem crossdraft gasifier dapat dilihat pada gambar .

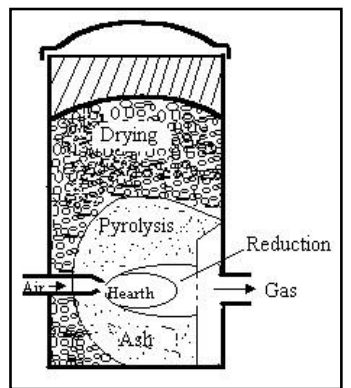

\section{Gambar 2.3 Crossdraft Gasifier}

Setiap alat gasifikasi memiliki karakterisik tersendiri yang membedakan suatu sistem gasifikasi dengan sistem gasifikasi yang lain. Hasil reaksi dan syngas yang dihasilkan dari reaksi gasifikasi tersebut dipengaruhi oleh karakteristik masing-masing alat gasifikasi tersebut. Berikut tabel kelebihan dan kekurangan berbagai tipe gasifier.

Tabel 2.1 Kelebihan dan Kekurangan Berbagai Tipe Gasifier

\begin{tabular}{|cll}
\hline Tipe Gasifier & \multicolumn{1}{c}{ Kelebihan } & \multicolumn{1}{c}{ Kekurangan } \\
\hline Updraft & - Mekanismenya sederhana & - Sensitif terhadap tar dan uap \\
& - Hilang tekan rendah & bahan bakar \\
& - Efisiensi panas baik & - Memerlukan waktu start up \\
& - Arang (charcoal) habis & yang cukup lama untuk mesin \\
& terbakar & internal combustion. \\
& & \\
Downdraft & - Tidak terlalu sensitif & - Desain gasifier tinggi \\
& terhadap tar & - Tidak cocok untuk bahan \\
& - Dapat mudah beradaptasi & bakar biomassa yang \\
& dengan jumlah umpan & berukuran kecil \\
& biomassa & \\
& & \\
Crossdraft & - Desain gasifier pendek & - Sangat sensitif terhadap \\
& - Sangat responsif ketika & pembentukan terak \\
& diisi umpan biomassa & - Hilang tekan tinggi \\
& & - Proses hanya ditujukan untuk \\
& & arang kualitas tinggi \\
& & - Temperatur gas keluaran \\
& tinggi \\
\hline Sumber: Rinovianto, 2012 & \\
\hline
\end{tabular}

\subsection{Gas Mampu Bakar (Syngas)}

Gas mampu bakar atau yang lebih dikenal gas sintetik (syngas) merupakan campuran hidrogen dan karbonmonoksida. Kata sintetik gas diartikan sebagai pengganti gas alam yang dalam hal ini terbuat dari gas metana. Syngas merupakan bahan baku yang penting untuk industri kimia dan industri pembangkit daya. Syngas memiliki kepadatan energi kurang dari setengah kepadatan energi gas alam. Proses utama pembentukan syngas bersifat endotermik dengan nilai $\Delta \mathrm{H}^{\circ}=206$ $\mathrm{kJ} / \mathrm{mol}$ sedangkan syngas yang tidak di metanisasi biasanya memiliki kapasitas kalor sebesar 120 BTU/scf. Syngas yang digunakan sebagai bahan bakar seringkali dihasilkan dari batubara atau biomassa dan sampah rumah tangga yang telah melalui proses pyrolysis atau distilasi destruktif menjadi coke (karbon tidak murni) yang kemudian dilajutkan dengan menyemburkan uap dan udara.

\subsection{Kayu Karet}

Tanaman karet merupakan tanaman perkebunan/industri tahunan yang pertama kali ditemukan di Brazil dan mulai dibudidayakan pada tahun 1601. Di Indonesia, Malaysia, dan Singapura, tanaman karet dicoba dibudidayakan pada tahun 1876. Tanaman karet (Hevea Brasiliensis ) termasuk ke dalam divisi Sphermatophyta, Subdivisi Angiospermae, kelas Dicotylodonae, keluarga Euphorbiaceae, dan genus Hevea. Karet cukup baik dikembangkan didaerah lahan kering beriklim basah. Tanaman karet memiliki beberapa keunggulan dibandingkan dengan komoditas lainnya, yaitu: dapat tumbuh dengan baik pada ketinggian antara 1-600 meter diatas permukaan tanah, dengan suhu harian $25-30^{\circ} \mathrm{C}$. Derajat keasaman tanah yang paling cocokuntuk ditanami karet adalah 5-6, pada berbagai kondisi dan jenis lahan, masih mampu dipanen hasilnya meskipun pada tanah yang tidak subur. Pada tabel 4 dibawah ini bisa dilihat sifat fisis dan morfologi dari kayu karet.

\subsection{Sistem Pembersihan Gas}

Gas hasil pembakaran dalam gasifier biasanya masih bercampur dengan berbagai unsur yang tidak diperlukan dan gas keluaran masih memliki temperature tinggi. Unsur yang tidak diperlukan itu antara lain partikel padat (partikel yang tidak terkonversi), pengotor anorganik (halida, alkali, senyawa belerang dan nitrogen) dan kotoran organik (tar, aromatik dan karbon dioksida). Gas hasil pembakaran/gas mampu bakar ini akan 
direaksikan dengan udara untuk dibakar menjadi energi. Pembakaran gas ini merupakan reaksi sintesis sehingga gas yang dihasilkan harus lebih murni. Oleh karena itu, gas keluar didinginkan dan dibersihkan terlebih dahulu dengan cara melewatkan dalam suatu unit penyaring (filtrasi). Cara untuk membersihkan gas dari debu atau partikel yang tidak diinginkan, yaitu tar dengan filtrasi (scrubber). Sistem filrasi dibagi menjadi dua, yaitu venturi wet scrubber dan dry scrubber. Prinsip dasar dari semua jenis filtrasi sama yaitu membersihkan gas dari unsur-unsur seperti senyawa sulphur, nitrogen, debu yang terangkut oleh gas, kelembaban dari gas, temperatur gas serta produk distilasi yaitu tar, minyak serta gas-gas yang tidak terkondendasi dan uap air.

\subsection{Metode Pengumpulan Partikel}

Venturi venturi wet scrubber menangkap partikel debu yang relatif kecil terhadap butiran liquid yang besar. Di kebanyakan venturi venturi wet scrubber, droplet yang dihasilkan biasanya adalah lebih kecil dari 50 micrometer (dalam range 150500 micrometer). Distribusi ukuran partikel yang akan dibuang dalam sistem tergantung dari sumber. Contohnya partikel yang dihasilkan dari peralatan mekanik (crush atau grind) cenderung besar (di atas 10 micrometer), sedangkan partikel yang berasal dari combustion atau reaksi kimia akan memilliki partikel yang kecil (kurang dari 5 micrometer) atau berukuran submikrometer. Droplet atau butiran air dihasilkan dengan metode antara lain mengalirkan arus gas menuju kolom liquid. Droplet-droplet mengumpulkan partikel dengan menggunakan satu atau lebih mekanisme pengumpulan.

\subsection{Prinsip Dasar Venturi Venturi Wetscrubber}

Venturi wet scrubber adalah istilah yang digunakan untuk menggambarkan variasi alat yang menggunakan liquid untuk membuang polutan. Pada venture wet scrubber, arus gas kotor dibawa menuju kontak dengan liquid pencuci dengan cara menyemprotkan, mengalirkannya atau dengan metode kontak lainnya. Scrubber dapat didesain untuk mengumpulkan polutan partikel atau gas.

Venturi wet scrubber membuang partikel dengan cara menangkapnya dalam tetesan atau butiran liquid. Sedangkan untuk polutan gas proses venturi wet scrubber adalah melarutkan atau menyerap polutan ke dalam liquid. Butiran liquid yang masih terdapat dalam arus gas setelah proses pencucian selanjutnya harus dipisahkan dari gas bersih dengan alat lain yang disebut mist eliminator atau entrainment separator.

\subsection{Prinsip Dasar Venturi Venturi Wet Ccrubber}

Venturi wet scrubber adalah istilah yang digunakan untuk menggambarkan variasi alat yang menggunakan liquid untuk membuang polutan. Pada venture wet scrubber, arus gas kotor dibawa menuju kontak dengan liquid pencuci dengan cara menyemprotkan, mengalirkannya atau dengan metode kontak lainnya. Scrubber dapat didesain untuk mengumpulkan polutan partikel atau gas. Venturi wet scrubber membuang partikel dengan cara menangkapnya dalam tetesan atau butiran liquid.

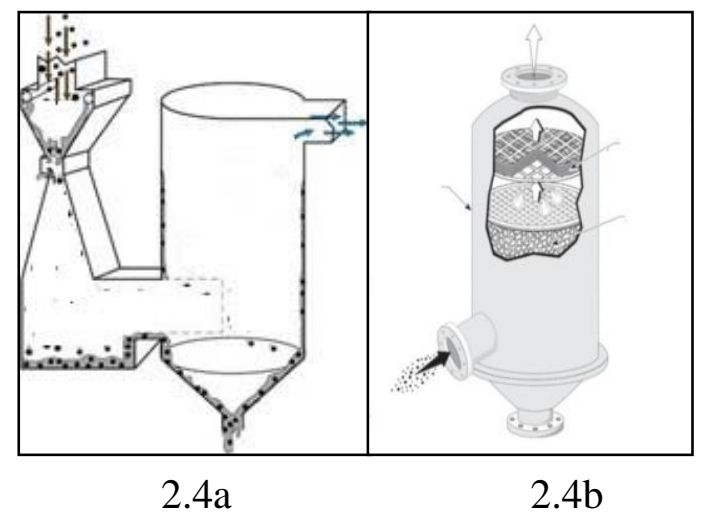

Gambar 2.4 Desain Venturi Wet Srubber

Sedangkan untuk polutan gas proses venturi wet scrubber adalah melarutkan atau menyerap polutan ke dalam liquid. Butiran liquid yang masih terdapat dalam arus gas setelah proses pencucian selanjutnya harus dipisahkan dari gas bersih dengan alat lain 
yang disebut mist eliminator atau entrainment separator. Terdapat banyak konfigurasi scrubber, semuanya didesain untuk menyediakan kontak yang baik antara liquuid dan gas kotor.

Gambar di atas menunjukkan dua contoh desain venturi wet scrubber, termasuk entrainment separator-nya. Gambar $2 \mathrm{a}$ adalah desain venturi scrubber yang digunakan dalam tugas akhir ini. Mist eliminator untuk scrubber biasanya adalah alat terpisah yang disebut cyclonic separator. Gambar $2 b$ memiliki desain tower dimana mist eliminator nya di atas struktur.

Venturi wet scrubber yang membuang polutan gas disebut absorber. Kontak gas liquid yang baik sangat penting untuk menghasilkan efisiensi pembuangan yang tinggi pada absorber. Apabila arus gas produser mengandung kedua polutan gas dan partikel, venturi wet scrubber secara umum adalah satu-satunya alat kendali polusi udara yang dapat membuang kedua jenis polutan. Venturi wet scrubber dapat memperoleh efisiensi pembuangan yang tinggi untuk polutan partikel atau gas, bahkan pada contoh tertentu, dapat memperoleh efisiensi pembuangan yang tinggi untuk kedua polutan pada sistem yang sama. Sebagai alat pengendali partikel, venturi wet scrubber memiliki beberapa keunggulan, yaitu :

a. Memiliki kemampuan untuk mengatasi temperatur dan kelembaban tinggi.

b. Menghasilkan kebutuhan ukuran peralatan yang lebih kecil secara keseluruhan.

c. Dapat membuang baik polutan gas maupun partikel padat.

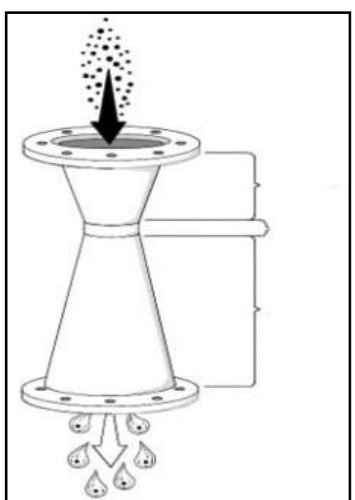

Gambar 2.5 Desain Scrubber

\subsection{Cara Kerja Venturi scrubber}

Gas yang masuk memiliki kecepatan yang tinggi sampai pada tenggorokan (throat) dari scrubber akan kontak dengan air yang masuk sebagai penangkap pengotor. Air akan diatomisasi ke dalam bentuk droplet-droplet yang akan menangkap partikel-partikel pengotor dengan efisiensi yang tinggi. Gas yang telah bersih akan berkurang kecepatannya dan masuk ke dalam separator, sedangkan droplet-droplet yang telah menangkap pengotor akan jatuh ke bagian bawah dari scrubber yang telah terbanjiri, sehingga mudah untuk dibuang. Dropletdroplet yang kecil akan terkumpul juga pada saat gas masuk ke dalam separator. Penurunan tekanan pada saat melewati throat scrubber menjadi suatu ukuran dari energi yang diperlukan untuk membuat droplet-droplet dan performa dari permbersihan gas.

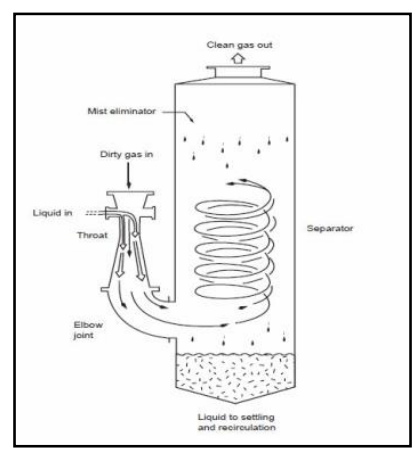

Gambar 2.6 Skema Aliran Gas pada Venturi Scrubber

\section{METODOLOGI PENELITIAN}

\subsection{Alat dan Bahan}

a. Alat yang digunakan, yaitu:

Combusion chamber yang terdiri dari: combustor, pembuangan abu dan grate.

Gas cleaning yang terdiri dari Venturi scrubber dan separator.

1. Pelat orifice,

2. Blower,

3. Pompa,

4. Pipa dan alat sambung,

5. Termokopel,

6. Manometer,

7. Water rotameter,

8. Burner, dan

9. Gas chromatography. 
b. Bahan yang digunakan, yaitu:

1. Kayu karet,

2. Tempurung kelapa,

3. Air, dan

4. Minyak tanah.

\subsection{Prosedur Percobaan}

1. Persiapan Bahan Bakar

Bahan bakar yang akan digunakan adalah kayu karet tua yang sudah ditebang dan didiamkan beberapa waktu. Kayu karet ini didapat dari petani yang melakukan regenerasi perkebunan karet tua di wilayah Sumatera Selatan, khususnya di Prabumulih. Kayu karet ini sebelum digunakan sebagai bahan bakar harus dipotong kecil berbentuk kubus dengan dimensi ukuran $3 \mathrm{~cm}$ x $3 \mathrm{~cm}$. Setelah dipotong kayu karet di keringkan dengan bantuan sinar matahari selama 2 jam. Kayu karet yang sudah dikeringkan ini kemudian dimasukan kedalam kantung plastik masing-masing seberat $5 \mathrm{~kg}$ per kantungnya.

2. Persiapan alat ukur

Alat ukur yang digunakan untuk pengujian terdiri dari plat orifice, manometer, termokopel,rotameter, dan neraca analitik (timbangan). Masing-masing alat ukur dipasang sesuai skema instalation set up dan pastikan tidak ada kebocoran di tempat pemasangannya. Manometer dipasang pada P1 dan P2 di setiap orifice meter dengan mengunakan selang silikon tahan panas. Untuk rotameter di bersihkan dulu tar yang terdapat di dalamnya dengan cairan aseton guna mempermudah pembacaan skala pengukuran.

\subsection{Prosedur Penelitian}

1. Proses pembakaran awal (start up)

a. Membuka baut yang terpasang pada tutup combustor.

b. Memasukkan kayu karet sebanyak $\pm 0,5$ $\mathrm{kg}$ ke dalam combustor gasifikasi, kemudian siram dengan miyak tanah (kerosene).

c. Menghidupkan blower yang dikontakkan dengan listrik, kemudian mengatur bukaan katup pada daerah aliran tiupan blower terbuka penuh (1800) dan valve pipa syngas dalam kondisi tertutup.

d. Menyulut bahan bakar di dalam combustor dengan api dan tunggu selama 5-15 menit atau sampai mendapatkan bahan bakar telah menjadi bara.

2. Prosedur gasifikasi (tanpa Venturi scrubber)

a. Setelah kayu karet menjadi bara, mematikan blower untuk sementara waktu.

b. Memasukkan tempurung kelapa $\pm 3,5 \mathrm{~kg}$ perlahan-lahan ke dalam combustor.

c. Menutup bagian atas combustor dengan memasang ke- 6 baut yang tersedia pada tutup dan mengencangkannnya.

d. Menghidupkan kembali blower.

e. Mengatur bukaan katup pada daerah aliran tiupan blower hingga manometer $\mathrm{U}$ menunjukkan nilai $\Delta \mathrm{h}$ sebesar $0,6 \mathrm{~mm}$ $\mathrm{H}_{2} \mathrm{O}$ atau dengan kata lain, laju aliran udara sebesar 108 lpm (berdasarkan referen), dan valve pada pipa syngas dibuka penuh.

f. Menunggu 15-30 menit sampai timbul asap pekat di burner.

g. Setelah terlihat asap pekat, melakukan penyulutan dengan pemantik di ujung burner. Bila belum terlihat, lakukan berulang-ulang.

h. Waktu ke -0 menit dilihat setelah lidah api terbentuk.

i. Pada menit ke- 15 mengambil data temperatur syngas yang masuk dan keluar venturi scrubber, beda tekan syngas yang masuk venturi scrubber.

j. Kemudian menyaring tar pada pipa keluaran separator tiap 15 menit selama 2 menit dalam 1 jam operasi.

3. Prosedur Gasifikasi (dengan Venturi scrubber)

Langkah-langkah yang dilakukan sama seperti prosedur gasifikasi tanpa venturi scrubber, namun pada langkah e menghidupkan pompa dan mengatur laju aliran air pada $15 \mathrm{lpm}$. Untuk laju aliran 20 
lpm dan 25 lpm langkah yang dilakukan sama.

\section{HASIL DAN PEMBAHASAN}

\subsection{Hasil Penelitian}

\subsubsection{Pengaruh Penggunaan Venturi}

Scrubber terhadap Komposisi Syngas

Analisa terhadap komposisi syngas dilakukan di Laboraturium PT Pupuk Sriwidjaja Palembang. Produk syngas yang dilakukan analisa merupakan produk tanpa penggunaan venturi scrubber dan dengan penggunaan venturi scrubber. Berdasarkan analisa yang dilakukan, maka tabel analisa hasil komposisi syngas dapat dilihat pada tabel 4.1 .

Tabel 4.1 Analisa Komposisi Syngas

\begin{tabular}{ccc}
\hline \multirow{2}{*}{ Komponen } & \multicolumn{2}{c}{ Komposisi (\% Mol) } \\
\cline { 2 - 3 } & Sebelum VS & Setelah VS \\
\hline $\mathrm{CO}$ & 10,15 & 9,05 \\
$\mathrm{H}_{2}$ & 3,74 & 3,43 \\
$\mathrm{CH}_{4}$ & 2,62 & 4,11 \\
\hline
\end{tabular}

Analisa tersebut diambil dari produk syngas yang dihasilkan pada laju aliran 0,025 $\mathrm{m}^{3} /$ min (setelah venturi scrubber). Pemilihan pada laju aliran air $25 \mathrm{~m}^{3} / \mathrm{min}$ ini akan dijelaskan pada pembahasan. Sedangkan untuk data sebelum venturi scrubber diambil dari produk syngas tanpa penggunaan venturi scrubber.

\subsubsection{Pengaruh Penggunaan Venturi Scrubber terhadap Nilai LHV Syngas}

Berdasarkan hasil analisa komposisi syngas, maka nilai LHV dari syngas tersebut dapat diketahui dari perhitungan. Tabel LHV syngas dapat dilihat pada tabel 4.2.

Tabel 4.2 Nilai LHV Syngas Produk Syngas

\begin{tabular}{cc}
\hline Produk Syngas & LHV $\left(\mathrm{MJ} / \mathrm{m}^{3}\right)$ \\
\hline Sebelum VS & 2,625 \\
Setelah VS & 2,987 \\
\hline
\end{tabular}

\subsubsection{Pengaruh Laju Alir Air Terhadap Efisiensi Kinerja Venturi Scrubber}

Berdasarkan penelitian yang telah dilakukan, diketahui massa tar yang mampu ditangkap oleh air dari sistem gas cleaning ( Venturi Scrubber). Dari massa tar ini, kemudian dapat diketahui efisiensi kinerja Venturi Scrubber berdasarkan langkahlangkah perhitungan yang ada di lampiran 2 . Data efisiensi kinerja Venturi Scrubber dapat dilihat pada tabel 4.3.

Tabel 4.3 Efisiensi Kinerja Venturi Scrubber

\begin{tabular}{ccccc}
\hline $\begin{array}{c}\text { Laju Aliran } \\
\text { Udara Primer } \\
\left(\mathrm{m}^{3} / \mathrm{min}\right)\end{array}$ & $\begin{array}{c}\text { Kandungan } \\
\text { Tar Sebelum } \\
\text { Venturi } \\
\text { Scrubber } \\
\left(\mathrm{gr} / \mathrm{m}^{3}\right)\end{array}$ & $\begin{array}{c}\text { Laju Aliran } \\
\text { Air }\left(\mathrm{m}^{3} / \mathrm{min}\right)\end{array}$ & $\begin{array}{c}\text { Kandungan } \\
\text { Tar Setelah } \\
\text { Venturi } \\
\text { Scrubber } \\
\left(\mathrm{gr} / \mathrm{m}^{3}\right)\end{array}$ & $\begin{array}{c}\text { Efisiensi } \\
(\%)\end{array}$ \\
\hline 0,108 & 7,345 & 0,015 & 7,147 & 31,962 \\
0,108 & 6,925 & 0,02 & 6,281 & 40,206 \\
0,108 & 6,925 & 0,025 & 3,141 & 70,103 \\
\hline
\end{tabular}

\subsection{PEMBAHASAN}

\subsubsection{Pengaruh Venturi Scrubber Terhadap Komposisi Syngas}

Gas yang dihasilkan pada pengujian dianalisa untuk mengetahui komposisi apa saja yang terkandung didalamnya, dimana gas yang diharapkan berupa syngas seperti $\mathrm{CH}_{4}, \mathrm{CO}$ dan $\mathrm{H}_{2}$. Melihat laju alir optimum terjadi pada kondisi laju alir $0,025 \mathrm{~m}^{3} / \mathrm{min}$, maka gas yang dianalisa hasil dari pengujian laju alir tersebut. Berdasarkan hasil analisa komposisi syngas di laboratorium PT Pupuk Sriwidjaja dengan menggunakan alat gas chromatografi, didapatkan hasil yang cukup berbeda antara syngas sebelum dan sesudah penggunaan venturi wet srubber, sebagaimana bisa dilihat pada grafik berikut.

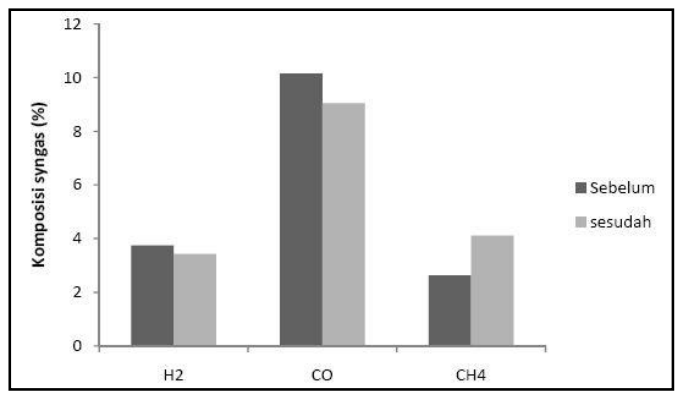

Gambar 4.1 Grafik Komposisi Syngas Sebelum dan Sesudah Scrubber 
Indikator bahwa suatu proses gasifikasi berhasil adalah adannya komposisi $\mathrm{CH}_{4}, \mathrm{CO}$ dan $\mathrm{H}_{2}$. Komposisi $\mathrm{H}_{2}$ pada grafik telihat menurun setelah penggunaan venture wet scrubber dari $3,74 \%$ menjadi $3,43 \%$, ini berarti terjadi penurunan komposisi $\mathrm{H}_{2}$ sebesar $0,31 \%$. Penurunan ini terjadi karena tar yeng terbentuk selama proses pembakaran mengandung $90 \% \mathrm{C}$ dan $10 \% \mathrm{H}$ (Chemical Process Principles Part I "Material and Energy Balances”: A Hougen, Hal :433 ).

\subsubsection{Pengaruh Venturi Scrubber Terhadap Nilai LHV (Low Heating Value) dari Syngas}

Nilai LHV merupakan nilai kalor dari suatu bahan bakar (dalam hal ini gas) dimana kandungan uap airnya sudah tidak ada lagi (dalam basis kering). Nilai LHV ini juga sering disebut NHV (Nett Heating Value) atau nilai kalor bersih. Nilai LHV dalam syngas ini dipengaruhi oleh analisa komposisi syngas yaitu gas mampu bakar, yaitu $\mathrm{CO}, \mathrm{CH}_{4}$ dan $\mathrm{H}_{2}$. Nilai LHV ini akan mempengaruhi nilai kalor dari suatu pengujian. Nilai LHV yang didapatkan pada penelitian ini merupakan hasil perkalian dari jumlah komposisi syngas (berdasarkan analisa komposisi gas) dengan nilai LHV gas (berdasarkan Data compiled from Jenkins, in Kitani and Hakk, 1989, dalam Kurniawan, 2012). Nilai LHV pada Tabel 12 menunjukan bahwa nilai LHV untuk $\mathrm{CH}_{4}$ sebesar 35,88 $\mathrm{MJ} / \mathrm{m}^{3}$ sedangkan $\mathrm{CO}$ dan $\mathrm{H}^{2}$ masing-masing $12,63 \quad \mathrm{MJ} / \mathrm{m}^{3}$ dan 10,78 $\mathrm{MJ} / \mathrm{m}^{3}$. Dari grafik terlihat terjadi peningkatan nilai LHV syngas setelah melewati wet scrubber. Sebelum melewati wet scrubber nilai LHV syngas sebesar $2,625 \mathrm{MJ} / \mathrm{m}^{3}$ dan meningkat menjadi $2,987 \mathrm{MJ} / \mathrm{m}^{3}$ setelah melewati wet scrubber. Peningkatan nilai LHV ini dipengaruhi oleh komposisi gas yang dihasilkan selama proses gasifikasi dan sudah dijelaskan pada pembahasan sebelumnya bahwa syngas yang melewati wet scrubber mengalami waktu reaksi (residence time) yang lebih lama di dalam combustor gasifier karena terhambat oleh laju alir air sehingga gas $\mathrm{CH}_{4}$ lebih banyak dihasilkan.

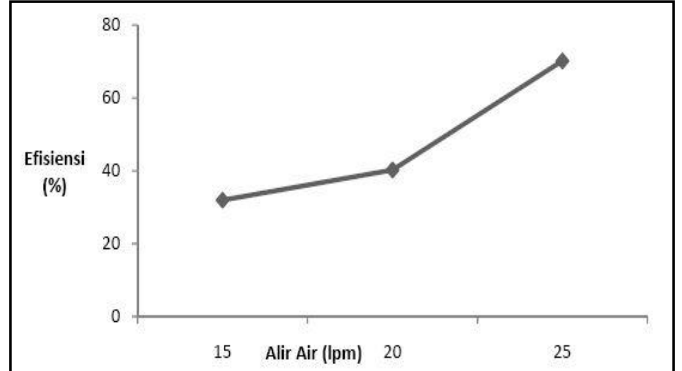

Gambar 4.1 Grafik Efisiensi Kinerja Venturi Scrubber Terhadap Laju Aliran Air

Dari gambar 4.1 dapat dilihat terjadi peningkatan efisiensi. Semakin besar laju aliran air yang digunakan, maka efisiensi akan semakin meningkat.

\section{KESIMPULAN DAN SARAN 5.1 Kesimpulan}

Dari hasil pengamatan dan pengujian yang telah dilakukan, maka diperoleh kesimpulan sebagai berikut :

1. Secara fungsional desain venture wet scrubber yang telah dirancang dan dibuat dapat bekerja menyerap tar pada syngas dengan laju alir air optimum sebesar 0,025 $\mathrm{m}^{3} /$ min dimana pada kondisi ini venturi wet scrubber mampu menangkap 1,7 gram tar dan mampu menurunkan temperatur syngas sampai $30^{\circ} \mathrm{C}$ serta memiliki tingkat efisiensi sebesar 70,103\% .

2. Syngas yang dihasilkan sebelum dan sesudah pemakaian wet scrubber mengalami perbedaan yang cukup signifikan masing-masing sebagai berikut ; CO $10,15 \%$, sebesar 9,05\%; $\mathrm{H}_{2} 3,74 \%$ sebesar $3,43 \%$ dan $\mathrm{CH}_{4} 2,62 \%$ sebesar $4,11 \%$ yang disebabkan oleh laju alir syngas yang keluar dari gasifier terhambat oleh laju alir air sehingga waktu reaksi (residance time) dalam gasifier menjadi lebih lama yang membuat proses reduksi menjadi optimal.

3. Nilai LHV (Low Heating Value) meningkat setelah melewati venturi scrubber yang pada kondisi sebelumnya sebesar 2,625 $\mathrm{MJ} / \mathrm{m}^{3}$ menjadi $2,987 \mathrm{MJ} / \mathrm{m}^{3}$. 


\section{DAFTAR PUSTAKA}

Bassu ,Prabir. 2010. Biomass Gasification and Pyrolisis : Practical Design.UK

Direktorat Jenderal Perkebunan. 2012. Produksi Karet Menurut Provinsi di Seluruh Indonesia.www.deptan.go.id

Gumanti,Ardyan Humala. 2012. Studi Kandungan Tar Pada Updraft Gasifier Dengan Double Syngas Outlet Menggunakan Bahan Bakar Kayu Karet.

Handika, Allin Indri. 2009. Studi Gasifikasi Batubara Menggunakan Gasifier Unggun Tetap Aliran Keatas. Universitas Sriwijaya : Indralaya

Hougen, Olaf A. , at al. 1961. Chemical Process Principle Part 1 Material and Energy Balance. Charles E. Tuttle Company : Tokyo

Khairumizan, Panji. 2008. Studi Eksperimental Implementasi Venturi Srubber Pada Sisteam Gasifikasi Batubara. Universitas Indonesia : Depok

Kurniawan. 2012. Karakteristik Konvensioanl Updraft Gasifier Dengan Menggunakan Bahan Bakar Kayu Karet Melalui Pengujian Variasi Flow Rate Udara. Universitas Indonesia : Depok

Mc Cabe, et al. 1993. Unit Operations of Chemical Engineering Fifth Edition. Mc. Graw Hill Inc. : Singapore

Nurtian, Irvan.2007. Perancangan Reaktor Gasifikasi Sekam Sistem Kontinu. Institut Teknologi Nasional : Bandung

Pahlevi, Reda. 2012. Skripsi : Pengaruh Laju Aliran Udara Primer dan Laju Aliran Air terhadap Temperatur Gas Mampu Bakar (Gas Produser) pada Sistem Gas Cleaning Gaifikasi Downdraft. Universitas Indonesia : Depok

Rinovianto, Guswendar. 2012. Karateristik
Gasifikasi Pada Updraft Double Outlet Gasifier Menggunakan Bahan Bakar Kayu Karet. Universitas Indonesia : Depok

Rifki, Mochammad A. 2012. Jurnal Sarjana Institut Teknologi Bandung Vol. 1 No.3 : Analisa Teknis Dan Ekonomi Pembangunan Pembangkit IGCC Berbahan Bakar Batubara Dengan CCS Di Propinsi DKI Jakarta. Institut Teknologi Bandung: Bandung

Universitas Indonesia : Depok Hall, D.O. Overend.R.P. 1987. Biomass Renerable Energy.Great Britain. 1987.

Vidian, Fajri. Gasifikasi Tempurung Kelapa Menngunakan Updraft Gasifier pada Beberapa Variasi Laju Alir Udara Pembakaran. Jurnal Teknik Mesin, vol.10 No.2 2008. 
P-ISSN: 2089-5925 E-ISSN: 2621-9328

Antrant

Jurnal Teknik Patra Akademika

PATA

Arademika

Volume 11 No. 01 Juli 2020 